\title{
A Learning Trajectory of Indonesian 12-years Old Students Understanding of Division of Fractions
}

\author{
Achmad Nizar, Siti Maghfirotun Amin, \& Agung Lukito \\ Faculty of Mathematics and Natural Science, Surabaya State University \\ achmad.nizar@gmail.com \\ amin3105@yahoo.com \\ gung_lukito@yahoo.co.id
}

\begin{abstract}
The purpose of this study was to describe mathematical hands-on activities that can support students to gain better understanding of dividing fractions. This preliminary research phase was started by testing, analyzing, and refining the initial hypothetical learning trajectory (HLT), then in the pilot experimental phase the revised HLT was implemented, and ended with the teaching experimental phase by developing a learning trajectory for 12 -year old students in understanding division of fractions. In developing the trajectory, a design research methodology was employed by using four contextual-based learning series (sharing biscuit, sharing remaining chocolate bar, arranging bedroom mats, and running around school yard), including providing some concrete materials or pictorial models as manipulative tools. Seven mathematics experts and twenty five 12-year old students were involved during the research. The four designed learning goals were determining the quotient of division of integer by proper fraction, proper fraction by integer, two proper fractions, and two fractions. Students succeeded in demonstrating their understanding and stated that $16: 1 / 2=32 ; 25 / 36: 5=5 / 36 ; 24 / 64: 1 / 2=6 / 8$; and 15/2:3/4 $=10$ respectively at the end of each designed activity. The interesting results of this study are not a proof, so that a much larger study is needed to determine if the results are due to this approach or due to the teachers' enthusiasm or what is known as the Hawthorne Effect.
\end{abstract}

Keywords: division of fractions, learning trajectory, understanding, contextual learning, design research

\section{Introduction}

The concepts of fractions have been known by Indonesian students informally through their daily life activities and are also introduced formally at primary and secondary levels. Although students have learned the concepts of fractions, their lack of understanding of particular concepts of fractions sometimes happens in their learning process (Rifa'at, Parvati, $\&$ Tambelu, 1996). Students' lack of opportunities to solve various daily life problems related to the concepts of fractions (Meng \& Sivasubramaniam, 2009) causes difficulty in assisting students to develop their formal thinking. This situation can lead to students' perception about how difficult it is to learn the concept of division of fractions. Consequently, their performance on tasks involving division on fractions is typically very poor (Gregg \& Gregg, 2007).

Students' difficulties in learning the concepts of division of fractions may be caused by the transition from 'teaching by telling' to 'students constructing' (Gravemeijer, 2004a). Under these circumstances, there is a belief that contextual learning can help the transition. In designing a contextual-based classroom learning activity for 12-year old students, teachers should know the four Piaget's stages of students' cognitive development. Valanides (1998) stated that 7-12 years old students are generally classified belonging to the concrete operational 
stage. In other words, 12-year old students will understand the construction of certain concepts with the help of concrete materials (Saondi, 2011). The use of suitable concrete materials and pictorial models are believed to support them to understand the concepts of division of fractions (Cramer, et al., 2010).

\section{Theoretical Framework}

\section{Division of Fractions}

According to Sinicrope, Mick, and Kolb (2002), division of fractions can generally be classified into five possible interpretations: (1) measurement division, (2) partitive division, (3) determination of a unit rate, (4) inverse of multiplication, and (5) inverse of a cartesian product. Measurement division 4:1/2 can be interpreted as: "How many halves in 4?" Using partitive division 8/3:4 can be interpreted by distributing eight thirds of pie among four people. The determination of a unit rate can be interpreted by answering the question "Andi can swim $20 \mathrm{~m}$ in $2 \frac{1}{2}$ minutes. How many meters can be swum by Andi in 1 minute?" In this case, the unit rate can be found by dividing 20 with $2 \frac{1}{2}$. By using inverse of multiplication, dividing $\mathrm{p} / \mathrm{q}$ by $\mathrm{r} / \mathrm{s}$ has the same meaning as multiplying $p / q$ by the inverse of $r / s$. The inverse of cartesian product interpretation is focused on the process of finding the missing length of rectangle with its area and one of its side's length are given.

\section{Students' Understanding}

It can be said that students understand if they can relate the new knowledge with the existing concepts in students' scheme (Skemp, 1987). Their representation of thinking becomes an indicator that they have understood particular concepts. Students can take advantage of graphical and symbolic languages to explore their thinking and allow teachers a window on children's understandings (Worthington, 2005). Knowledge and the importance of visual representations (pictorial models) are needed since pictorial model is a powerful cultural tool that supports learning and has an important role in students' developing understanding (Worthington, 2005). At this point, students' verbal communication, representation of their thinking, and solution can be the indicator of their understanding.

\section{Learning Trajectory}

Learning trajectory is a description of the learning activities route that can be understood by students in building their understanding. Simon (as cited in Armanto, 2002) defined the learning trajectory as hypothetical learning trajectory (HLT). HLT consists of three main components namely: learning goals, learning activities that can be used to support learning, and conjectured learning and thinking (Simon \& Tzur, 2004). The conjectured learning and thinking can be the result of the thinking and learning process created by students during their learning of certain concepts (Winarti, 2011). 


\section{Method}

Design research becomes the focus of this study. Design research is implemented in three phases, they are preliminary design, teaching experiment, and retrospective analysis (Gravemeijer, 2004b). Preliminary design is started by clarifying the learning objectives and listing the anticipation actions during the learning process to form initial HLT. Teaching experiment emphasizes on the testing of initial HLT to form revised HLT while retrospective analysis is aimed to compare the revised HLT with the actual learning process.

\section{Student Selection}

This study is divided into two parts, pilot experiment and teaching experiment. The pilot experiment was conducted based on the initial HLT and the teaching experiment was implemented based on the revised HLT. Both the pilot and the teaching experiment were conducted in SD Laboratorium, Surabaya State University. During the pilot experiment, six 12year old students were involved. After doing several improvements, the revised HLT was implemented to the whole class of twenty 12-year old students in real teaching experiment.

\section{Data Collection}

The procedures used to collect the data during the study were pre-test and post-test, observations, interviews, and questionnaire. The collected data was analyzed retrospectively using the HLT as a guide. All the learning processes were recorded and transcribed. The process of data analysis involved an external panel of mathematics experts to provide a different interpretation. Data triangulation, HLT, and the external panel were used to ensure the validity of the instruments used in the study while cross interpretation and track ability were techniques for measuring the reliability.

\section{Teaching Episodes}

This study emphasized how students learnt the four concepts of division of fractions. The summarized teaching episodes (see Table 1), including its tasks, have been checked by the expert panel of five mathematics experts from Surabaya State University.

Table 1.

Teaching Episodes and Tasks

\begin{tabular}{llll}
\hline No & Activity & Objective & Description \\
\hline 1 & Sharing Biscuit & $\begin{array}{l}\text { Finding the quotient } \\
\text { of integer by proper } \\
\text { fraction }\end{array}$ & $\begin{array}{l}\text { This activity is designed to support students in distributing } \\
\text { halves of biscuits among several students. The students are } \\
\text { asked to find the number of students who get half of the } \\
\text { biscuit. }\end{array}$ \\
\hline Sharing & $\begin{array}{l}\text { Remaining } \\
\text { Chocolate Bar }\end{array}$ & $\begin{array}{l}\text { Finding the quotient } \\
\text { of proper fraction by } \\
\text { integer }\end{array}$ & $\begin{array}{l}\text { This activity is designed to support students in distributing } \\
\text { the remaining chocolate bar among some students. The } \\
\text { students are asked to find the fraction received by each } \\
\text { student. }\end{array}$ \\
\hline
\end{tabular}




\begin{tabular}{llll}
\hline No & Activity & Objective & Description \\
\hline 3 & $\begin{array}{l}\text { Arranging } \\
\text { Bedroom Mats }\end{array}$ & $\begin{array}{l}\text { Finding the quotient } \\
\text { of two proper } \\
\text { fractions }\end{array}$ & $\begin{array}{l}\text { This activity is designed to support students in finding the } \\
\text { missing length of a bed if the area and the width of the bed } \\
\text { are given. Students are asked to find the length of the bed. }\end{array}$ \\
\hline 4 & $\begin{array}{l}\text { Running Around } \\
\text { School Yard }\end{array}$ & $\begin{array}{l}\text { Finding the quotient } \\
\text { of two fractions }\end{array}$ & $\begin{array}{l}\text { This activity is designed to support students in determining } \\
\text { how long it takes to run 1/4 lap and one full lap of the } \\
\text { yard. }\end{array}$ \\
\hline
\end{tabular}

\section{Results}

\section{Designing the Initial and Revised HLT}

The initial HLT was formed in the preliminary design phase where two mathematics experts and a mathematics teacher involved. The research was continued by testing the initial HLT in the pilot experimental phase. The information and experiences obtained from this phase became a consideration in redesigning the initial set of learning activities that had been developed and to find other new conjectured learning and thinking of students' mental activities. Three groups consisting of two students each were involved during this pilot experiment in order to form the revised HLT (see Appendix).

\section{Teaching Experimental Phase}

\section{Activity 1}

Students' interpretation of division of fractions as measurement division became the mathematical idea for conducting this activity. According to students' answer in figuring out the given prerequisites, students succeeded in showing how to represent the fraction using the appropriate pictorial model or visualizing the given fraction in its appropriate pictorial model. The following figure shows the problem and students' works in Activity 1.

\section{Problem 1}

Andi has 16 biscuits. He will share those biscuits with his friends that each person has a half of the biscuit. How many friends will get Andi’s biscuits?

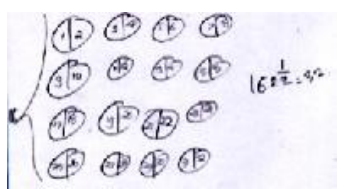

a. Group 3

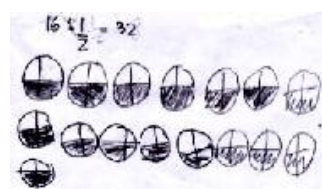

b. Group 4

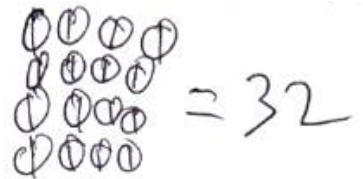

c. Group 5

Figure 1. Problem 1 and student's works in Activity 1

By considering Figure 1, Group 3 had sixteen representations of biscuits, drew a line in each pictorial model as a divider, and counted the number of halves. Group 5 left the pictorial models unshaded (see Figure 1.c) while Group 4 shaded one part of halves on each pictorial model (see Figure 1.b). Both groups also counted the number of halves mentally. Group 3 also left the pictorial models unshaded or uncolored, but they wrote number 1 to 32 as counter in determining the number of halves (see Figure 1.a). 
Group 3 succeeded with division of fractions as a measurement division. During the interview students stated that finding the quotient of 16:1/2 was similar with finding the number of halves in 16. Students in Group 4 did a more advanced model of division of fractions by using a unit rate. This unexpected idea was proved when students stated in the interview that if each student would get 1 biscuit then there were 16 students who get one biscuit, if there were 2 biscuits to be given to each student then there would be 32 biscuits, thus $16: 1 / 2$ was 32 . In the revised HLT, students also expected to do real cutting of biscuits. This expected action was shown when Group 1 and Group 2 tried to figure out the given problem by cutting the given biscuits.

\section{Activity 2}

Students' interpretation of division of fractions as partitive division became the mathematical idea in conducting this activity. According to students' answer in figuring out the given prerequisites, instead of using a circle, square, or other two-dimensional shapes, they used rectangles in representing fractions in the pictorial model. The following figure shows the problem and students' works during Activity 2.

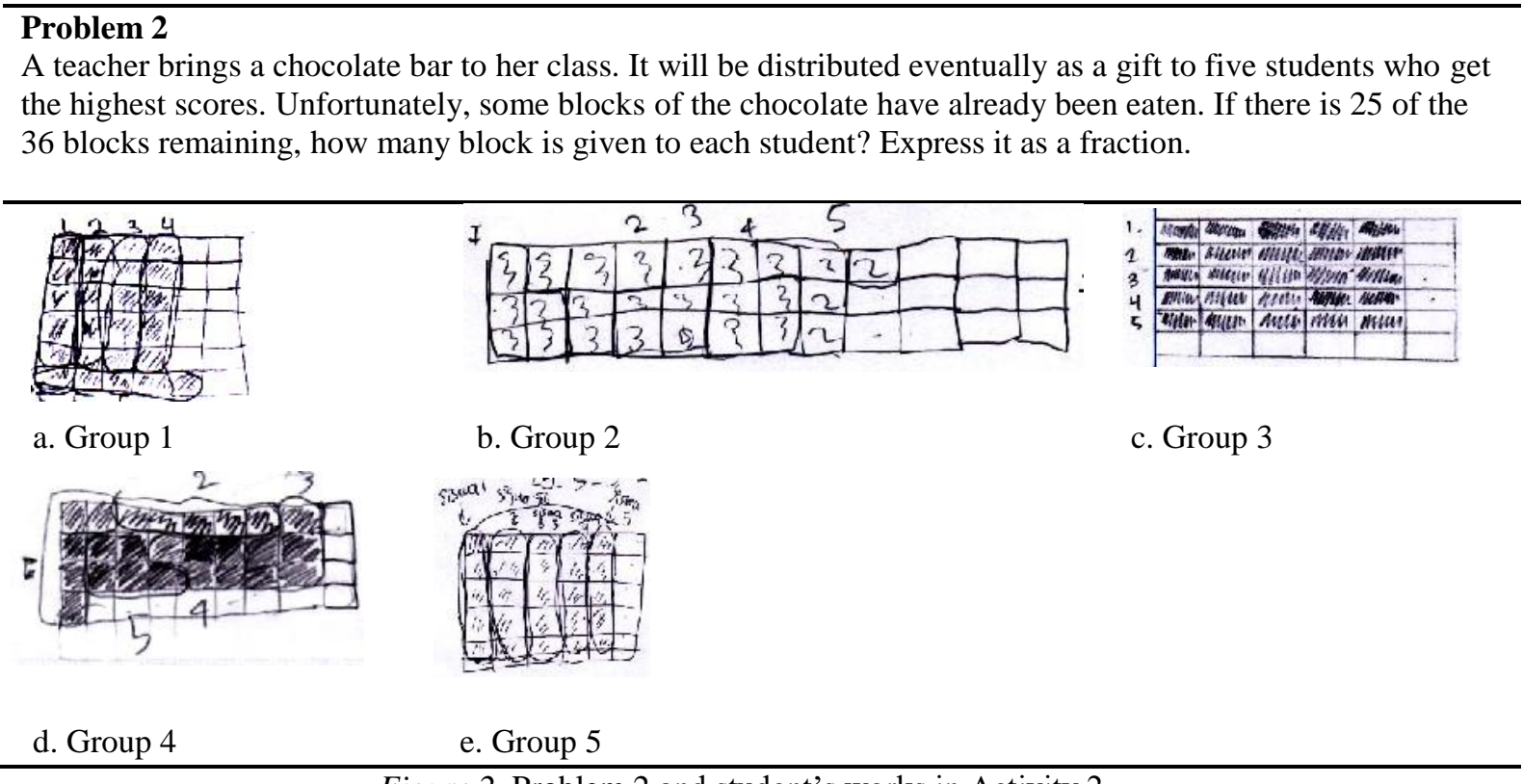

Figure 2. Problem 2 and student's works in Activity 2

Students knew that the remaining blocks could be represented as fraction 25/36. Students also succeeded in expressing the fraction in its appropriate pictorial model. Although they could sketch the pictorial model of fraction 25/36, in sketching the pictorial model of the remaining chocolate bar, students used several dimensions. Only students in Group 4 who sketched the pictorial model exactly the same with the dimension of the chocolate bar (see Figure 2.d). 
The activity continued by asking students to determine the number of blocks given to each student. Students stated that each student would get five blocks. As expected in the revised HLT, grouping became students' main idea. Some students grouped five blocks in each row (see Figure 2.c), some students grouped five blocks in each column (see Figure 2.e), and some students grouped five blocks in each row or column (see Figure 2.a). The rest of students grouped five adjacent blocks randomly. The next activity was asking students to form the blocks given to the students as a fraction. Most of them succeeded in forming the five blocks as a fraction $5 / 36$ by themselves, although some students needed to be guided to express it as a fraction $5 / 36$.

The interesting finding occurred when Group 1 and Group 4 wrote 25/36:5/1 = 5/36 on their sheets. After conducting interviews, students stated that the numerator of the quotient 5 could be found by dividing the numerator of the dividend by the numerator of divisor $(25 \div 5)$ and the denominator of the quotient 36 could be found by dividing the denominator of dividend by the denominator of divisor $(36 \div 1)$.

\section{Activity 3}

Students' interpretation of division of fractions as the inverse of a cartesian product became the mathematical idea for conducting this activity. According to students' answers in figuring out the given prerequisites, they showed their understanding in determining the certain length on each side of the square and the area of the rectangle. Figure 3 shows the problem and students' works in Activity 3.

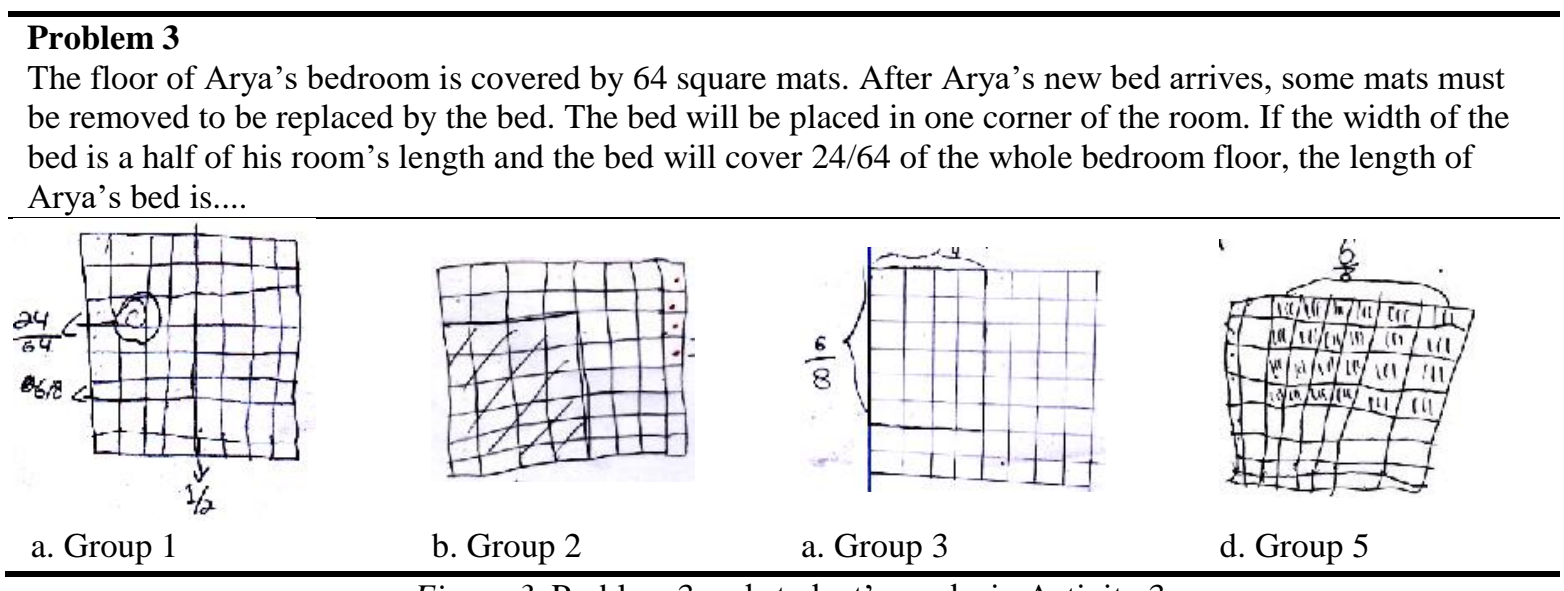

Figure 3. Problem 3 and student's works in Activity 3

In the beginning of the lesson, students were expected to sketch the bedroom and the bed. In order to support students in sketching, some models of puzzle mats were provided to each group. According to the collected data, students succeeded in forming the given models of the mats on the bedroom. The problem occurred when students in Group 4 had difficulty in arranging the mats. One student arranged the mats from top to bottom, while another student 
arranged the mats from left to right. Therefore, instead of arranging bedroom $8 \times 8$, the arranged bedroom's mats is $8 \times 9$. After several discussions, students in Group 4 agreed to form 8 mats from the left to the right and 8 mats from the top to the bottom.

It was also expected that students would choose in which corner the bed would be placed. Four groups did what was expected in the revised HLT by sketching the pictorial model of the bedroom and the bed (see Figure 3). Only Group 4 which did not sketch the pictorial model of the bedroom and the bed on its sheet. Instead of sketching the arranged models on their answer sheet, they chose to leave the arrangement unsketched.

By considering Figure 3, since the width of the bed compared with the length of the bedroom was $1 / 2$, students divided the length of the bedroom by 2 and took one part as the width of the bed. As expected in the revised HLT, it was possible for students to write $1 / 2$ as the width of the bed on their pictorial models (see Figure 3.a), although students were also expected to leave the width unmarked (see Figure 3.b). Since the area of the bed was $24 / 64$, students removed 24 mats. Unfortunately, a similar problem that occurred in the pilot experimental phase also happened in this activity. Group 3 removed 24 of 64 mats without first considering the given conditions.

The next step was determining the length of the bed compared with the length of the bedroom. It was expected that students would state that $3 / 4$ of the side of the bedroom became the length of the bed. Unfortunately, no students simplified the length of the bed. They used 6/8 instead of 3/4 (see Figure 3a, Figure 3.c, and Figure 3.d). As stated before, Group 4 used a different way in answering the given problem. Instead of sketching the arrangement of the square mats as a pictorial model, students explained their answer in written form. The interesting finding was that the consistency of this group in expressing the given questions as a division of fractions. Students in Group 4 ended their answer on Activity 1, 2, and 3 respectively as $16: 1 / 2=32,25 / 36: 5 / 1=5 / 36$, and 24/64:1/2 $=6 / 8$.

\section{Activity 4}

Students' interpretation about division of fractions as the determination of a unit rate became the mathematical idea in conducting this activity. According to students' answer in figuring out the given prerequisite problems, they had understanding in determining the certain length on each side of square and determining the area of rectangle. The following figure shows students' work on Problem 4. 


\section{Problem 4}

Before doing some physical exercises, Andi must run one full lap around his school square-shaped yard as a warm-up activity. Andi can reach 3/4 round of the yard in 15/2 minutes.

(a) How long does it take to reach $1 / 4$ around the yard?

(b) How long does it take to reach one full lap of the yard?

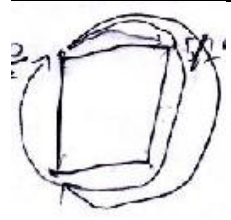

a. Group 1

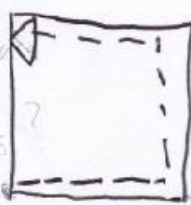

b. Group 2

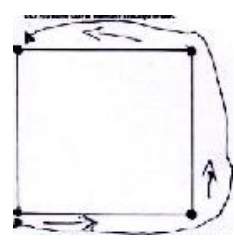

c. Group 3

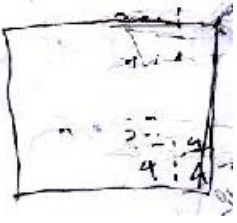

d. Group 4

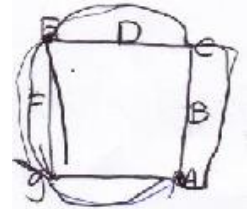

e. Group 5

Figure 4. Problem 4 and student's works in Activity 4

In the beginning of the lesson, students succeeded in sketching the school yard (see Figure 4). Most of them inserted the given route on their pictorial models. Unfortunately, no students wrote 3/4 as the route travelled by Andi and 15/2 as the time duration to travel the route. According to the route sketched on the pictorial model, actually students knew that $3 / 4$ round of the yard had the meaning of travelling from the bottom left to the top left corner of the yard or its reverse (consider the arrow made by students in Figure 4.c) except students in Group 4 (see Figure 4.d). Group 4 understood 3/4 round of the yard by interpreting the fraction $3 / 4$ as part of a whole. The whole route of the running had a meaning of travel to all four sides of the yard. Since, it was known that Andi only travels 3/4 round of the yard, so only 3 of 4 sides were travelled by Andi.

According to the collected data, students succeeded in determining the duration needed by Andi to travel 1/4 round of the yard. It was $5 / 2$ minutes to travel $1 / 4$ around the yard. In determining the $5 / 2$ minutes, some students wrote $15 / 2: 3=5 / 2$ or $15 / 2: 3 / 1=5 / 2$ on their sheets. Students said that since $3 / 4$ had a meaning three quarters, so to find the duration of a quarter, they needed to divide $15 / 2$ by 3 . The interesting finding occurred when Group 2 stated 15:3= $5=5 / 2$ on their sheet. It was known that students tried to simplify $15 / 2$ by 15 and kept the $1 / 2$ on their mind. After finding the quotient of 15 by 3 , they wrote back the $1 / 2$ to form $5 / 2$ as its answer. Although this idea was not expected in the revised HLT, it could be said that their idea still fitted with the expected actions.

The activity continued by asking students to answer the second question about determining the duration needed by Andi to travel one full lap of the yard. In determining the duration, it was expected that students would add the duration for $3 / 4$ round which was $15 / 2$ minutes, and the duration for $1 / 4$ round which was $5 / 2$ minutes to form 10 minutes. This expectation occurred when students in Group 1, Group 2, and Group 5 answered the question. Group 1 knew that another 1/4 lap of the yard was needed to form one full lap of the yard. Therefore, instead of simply writing the time duration to travel one full lap of the yard, which was 20/2 minutes, Group 1 also sketching the route of the given situation. 
The interesting findings occurred when Group 2 and Group 5 proposed their answers. Similar to the idea of Group 1, they knew that another 1/4 lap of the yard was needed. Therefore they added the durations, but instead of adding $15 / 2$ and $5 / 2$, they wrote $15+5=20$. After conducting some interviews, it was proved that students tried to simplify $15 / 2$ and $5 / 2$ by adding 15 and 5 respectively and kept $1 / 2$ on their mind. After finding the sum of 15 by 5 , then they wrote back $1 / 2$ to form $20 / 2$ as its answer.

In determining the duration of one full lap of the yard, it was also expected that students multiplied the duration for $1 / 4$ round, which was $5 / 2$ minutes, by 4 to form 10 minutes. This expectation occurred when Group 3 answered the question. This group knew that running one full lap of the yard had a meaning running four sides of a square. Since 5/2 minutes was needed to travel on one side of the yard, to travel on all four sides of the yard students just multiplied the needed duration to travel on one side by 4 to from 20/2 minutes.

\section{Conclusion}

\section{Dividing Integer by Proper Fraction}

The 'Sharing Biscuit' aimed at supporting students to understand the division of an integer by a proper fraction. By interpreting the division of fractions as measurement division, they succeeded in showing their understanding about how to find the quotient of $12: 1 / 2$ or 16:1/2. This finding was in line with the study conducted by Holisin (2002) that stated the use of a concrete approach associated with the use of concrete material was effective to assist students to get better understanding on the division of fractions.

\section{Dividing Proper Fraction by Integer}

The 'Sharing Remaining Chocolate Bar' aimed to support students in understanding the division of a proper fraction by an integer. By interpreting the division of fractions as partitive division, students succeeded in showing their understanding of how to find 25/36:5. By proposing a contextual distribution of the remaining chocolate bar, which is $25 / 36$ among five students, they could interpret 25/36:5 by distributing 25 blocks of $1 / 36$ among five students and calculating the number of 1/36's gotten by each student as the quotient of 25/36:5.

\section{Dividing Two Proper Fractions}

The 'Arranging Bedroom Mats' was meant to support students in understanding the division of two proper fractions. In this activity, instead of using the real mats, researchers used the paper model of mats. By interpreting the division of fractions as the inverse of a cartesian product, they succeeded in showing their understanding of how to find the quotient of $8 / 64: 1 / 4$ or 24/64: 1/2. By proposing a contextual problem finding the length of the bed if the area and 
the width of the bed is $8 / 64$ and $1 / 4$ respectively, they were able to show their understanding that the length of the bed can be found by dividing the area by the width of the bed.

\section{Dividing Two Fractions}

The 'Running Around School Yard" was designed to support students in understanding the division of two fractions. This activity was intended to avoid the use of concrete material. They used the satellite image of the students' school yard as the learning media to manipulate the concrete material. By interpreting the division of fractions as the determination of the unit rate, they succeeded in showing their understanding of how to find the quotient of 15/2:3/4. They were able to show their understanding in finding the duration to run one full round of the yard by dividing $15 / 2$ by $3 / 4$.

\section{References}

Armanto, D. (2002). Teaching multiplication and division realistically in Indonesia primary schools: A prototype of local instructional theory (Doctoral's dissertation). University of Twente, Endschede.

Cramer, K., Monson, D., Whitney, S., Leavitt, S., \& Wyberg, T. (2010). Dividing fractions and problem solving. Mathematics Teaching in the Middle School, 15(6), 338-346.

Gravemeijer, K. (2004a). Creating opportunities for students to reinvent mathematics. Paper presented at the $10^{\text {th }}$ International Congress on Mathematical Education (ICME), Copenhagen, Denmark.

Gravemeijer, K. (2004b). Local instruction theories as means of support for teachers in reform mathematics education. Mathematical Thinking and Learning, 6(2), 105-128. https://doi.org/10.1207/s15327833mt10602_3

Gregg, J., \& Gregg, D. U. (2007). Measurement and fair-sharing models for dividing fractions. Mathematics Teaching in the Middle School, 12(9), 490-496.

Holisin, I. (2002). Pembelajaran pembagian pecahan di SD dengan menggunakan pendekatan konkrit dan semikonkrit (Master's thesis). Universitas Negeri Surabaya, Surabaya.

Meng, W. L., \& Sivasubramaniam, P. A. P. (2009). The conceptual understanding of fractions as part of a set among year 5 students. Paper presented at the $3^{\text {rd }}$ International Conference on Science and Mathematics Education (CoSMEd), Penang, Malaysia.

Rifa'at, M., Parwati, N. N., \& Tambelu, J. V. A. (1996). Pembelajaran pengertian pecahan bersama siswa kelas satu SMP IKIP Malang. Forum Penelitian Kependidikan, 8, 7182. 
Saondi, O. (2011). Psikologi belajar matematika [blog post]. Retrieved from https://mathedu08.files.wordpress.com/2010/05/psikologi-belajar-matematikadiktat.doc

Simon, M. A., \& Tzur, R. (2004). Explicating the role of mathematical tasks on conceptual learning: An elaboration of the hypothetical learning trajectory. Mathematical Thinking and Learning, 6(2), 91-104. https://doi.org/10.1207/s15327833mt10602_2

Skemp, R. R. (1987). The psychology of learning mathematics. New York: Routledge.

Valanides, N. (1998). Formal operational performance and achievement of lower secondary school students. Studies in Educational Evaluation, 24(1), 1-23. https://doi.org/10.1016/s0191-491x(98)00001-7

Winarti, D. W. (2011). Learning the concepts of area and perimeter by exploring their relation (Master's thesis). Universitas Negeri Surabaya, Surabaya.

Worthington, M. (2005). Reflecting on creativity and cognitive challenge: visual representations and mathematics in early childhood - some evidence from research. Retrieved from http://www.tactyc.org.uk/pdfs/Reflection-worthing ton.pdf Zulkardi. (2000). Realistic mathematics education theory meets web technology. Paper presented at the National Conference on Mathematics, Bandung, Indonesia. 


\section{APPENDIX}

\section{Conjectured Learning and Thinking (CLT)}

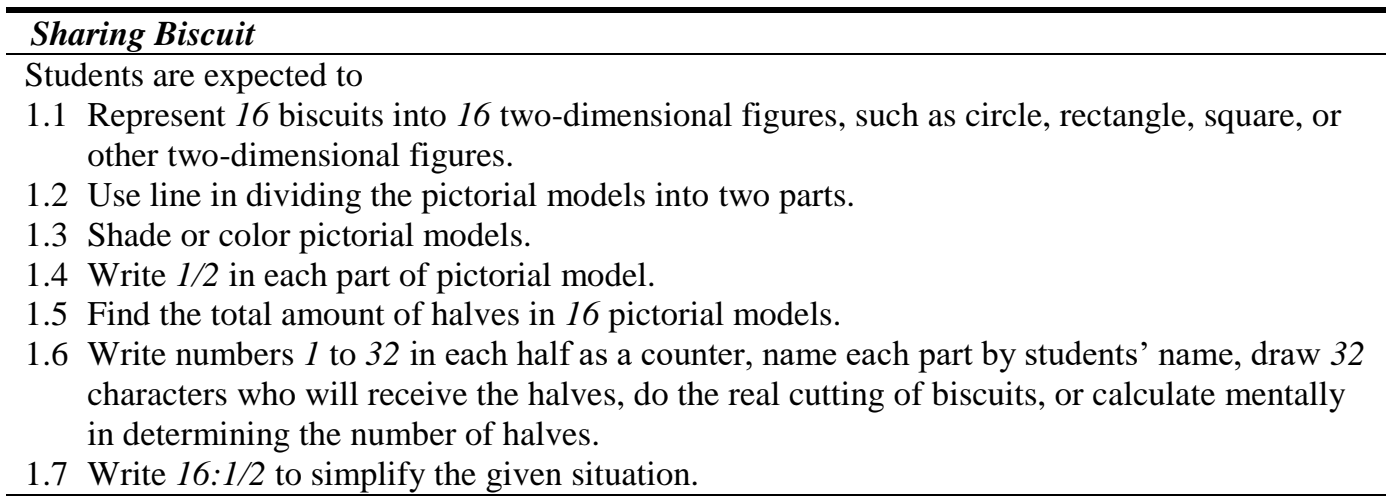

\section{Sharing Remaining Chocolate Bar}

Students are expected to

2.1 Visualize the remaining blocks into its pictorial model.

2.2 Use two-dimensional figures to create pictorial model.

2.3 Shade or color the regions that represent the eaten blocks.

2.4 Express fractions $25 / 36$ as 25 times of $1 / 36$.

2.5 Write numbers 1 to 25 on each tiles as a counter or do the calculation mentally in determining the number of $1 / 36$.

2.6 Distribute 25 pictorial models of fractions $1 / 36$ eventually among 5 students.

2.7 Draw 5 characters of students in representing 5 students.

2.8 Draw all pictorial models of fractions $1 / 36$ received by each student, group every 5 regions, or use some arrows in showing the distribution.

2.9 Represent those 5 pictorial models of fractions $1 / 36$ received by each students as pictorial model of fractions $5 / 36$.

\section{Arranging Bedroom Mats}

Students are expected to

3.1 Sketch the bed in the room and determine the width of bed which is $1 / 2$ length side of the room.

3.2 Sketch a square having 64 mats.

3.3 Place pictorial model of bed horizontally or vertically in one of the corners of the room.

3.4 Use other concrete materials to represent the bed.

3.5 Write $1 / 2$ as the width of bed.

3.6 Sketch the bed on pictorial model whose area is $24 / 64$ of the area of the room.

3.7 Shade, color, or write symbols such as dots on the mats that will be replaced by the bed.

3.8 Answer the length of the bed which is 6 units.

3.9 Determine the length of the bed as $6 / 8$ or $3 / 4$ length side of the room.

\section{Running Around School Yard}

Students are expected to

4.1 Create pictorial model of the field and insert the route travelled by Andi (3/4 round of the yard) in $15 / 2$ minutes on it.

4.2 Determine the duration needed to reach $1 / 4$ round of the yard, which is $5 / 2$ minutes.

4.3 Determine the position of $1 / 4$ round of the yard by dividing the route into 4 and take 1 part.

4.4 Divide the duration needed to travel $3 / 4$ round of the yard by 3 .

4.5 Do mathematical operation $15 / 2 \times 1 / 3=5 / 2$.

4.6 Determine that one full round of the yard can be reached in 10 minutes.

4.7 Add $15 / 2$ (duration for $3 / 4$ round) and 5/2 (duration of $1 / 4$ round), $15 / 2+5 / 2=20 / 2=10$ minutes, multiply $5 / 2$ (duration of $1 / 4$ round) by $4,5 / 2 \times 4=20 / 2=10$ minutes, or do partitive addition, $5 / 2+5 / 2+5 / 2+5 / 2=20 / 2=10$ minutes determining the duration to reach one full round of the yard.

4.8 Find the algorithm in finding the quotient of 15/2:3/4 $=10$. 